\title{
MicroRNAs as B-cell lymphoma biomarkers
}

This article was published in the following Dove Press journal:

Blood and Lymphatic Cancer:Targets and Therapy

4 February 2015

Number of times this article has been viewed

\section{Lorea Manterola'}

Marta Fernandez-Mercado'

Erika Larrea'

Ibai Goicoechea'

María Arestin'

María Armesto'

Luiza Hernandez'

Charles H Lawrie ${ }^{1,2,3}$

'Oncology Area, Biodonostia Research Institute, San Sebastián, Spain; ${ }^{2}$ Nuffield Department of Clinical Laboratory Sciences, University of Oxford, Oxford, UK; ${ }^{3}$ Ikerbasque, Basque Foundation for Science, Bilbao, Spain
Correspondence: Charles H Lawrie Oncology Area, Biodonostia Research Institute, Paseo Doctor Begiristain, 20014 San Sebastián, Spain Email charles.lawrie@biodonostia.org
Abstract: B-cell lymphomas represent a group of more than 35 recognized mature B-cell neoplasms differentiated largely on the basis of immunohistochemical staining patterns that are often challenging to accurately diagnose. Despite having been only formally recognized just over 10 years ago, microRNAs (miRNAs) have become one of the trendiest topics in biology. Dysregulation of miRNAs is a ubiquitous feature of cancer in general, including B-cell lymphomas. Many of the miRNAs aberrantly expressed in B-cell lymphomas also play a crucial regulatory role in normal hematopoietic function. MiRNAs show great potential as novel biomarkers of cancer, as they can differentiate cancers according to diagnosis and developmental stage, even discriminating between cancers that are poorly separated histologically. Furthermore, they can be robustly measured from routinely prepared formalin-fixed paraffin-embedded biopsy material and biological fluids such as blood. Here, we consider the identity, function, and biomarker potential of miRNAs in B-cell lymphomas and, most importantly, the hurdles that remain to be overcome if they are really to become part of future clinical practice.

Keywords: microRNA, lymphoma, biomarker, B-cell

\section{Introduction}

The central dogma of molecular biology states that biological information flows in one direction from DNA to RNA to protein. ${ }^{1}$ However, this view implies that noncoding RNA has little or no intrinsic value, despite accounting for more than $90 \%$ of eukaryotic transcriptional output. ${ }^{2}$ Therefore, it is perhaps not surprising that microRNAs (miRNAs) were unknown to the scientific community until just over 20 years ago and were not formally recognized until $2001 .^{1-5}$ There are now over 2,500 human miRNAs that have been identified through cloning and/or sequence analysis (miRBase) ${ }^{6}$ and it is believed that more than two-thirds of all human genes are a target for direct miRNA regulation. ${ }^{7}$ MiRNAs play key regulatory roles in virtually every aspect of biology including developmental timing, cell differentiation, apoptosis, cell proliferation, metabolism, organ development, and hematopoiesis. ${ }^{8}$ The potential importance of miRNAs in cancer is implied by the fact that the majority of human miRNAs are located at cancer-associated genomic regions. ${ }^{9}$ There is now overwhelming evidence that dysfunctional expression of miRNAs is a common, if not ubiquitous, feature of cancer in general including lymphomas. ${ }^{10,11}$ The reasons for the dysfunctional expression of miRNAs in cancers are numerous, and can include chromosomal aberrations, epigenetic deregulation, aberrant expression of transcription factors that regulate promoter regions of miRNAs, as well as factors that change miRNA biosynthesis and/or function. ${ }^{12}$ 
According to the National Cancer Institute, a biomarker is "a biological molecule found in blood, other body fluids, or tissues that is a sign of a normal or abnormal process or of a condition or disease." Cancer biomarkers are most commonly defined in three broad categories as being used for differential diagnosis (diagnostic), distinguishing between "good outcome tumors" and "bad outcome tumors" in the absence of treatment (prognostic), or assessing the probability that a patient will benefit from a particular treatment (predictive). As we will see, miRNAs have potential in all three of these categories.

The potential of miRNAs as cancer (diagnostic) biomarkers is clear, as differences in the expression profile of miRNAs can distinguish cancers according to the diagnosis and developmental stage of the tumor to a greater degree of accuracy than traditional gene expression analysis, even discriminating between cancers that are poorly separated histologically. ${ }^{13}$ This characteristic is especially attractive to the field of B-cell lymphomas (BCLs), a group of more than 35 recognized neoplasms ${ }^{14}$ differentiated largely on the basis of immunohistochemical staining patterns that are often challenging to accurately diagnose. ${ }^{15}$ The usefulness of molecular methods to supplement traditional morphological classifications in BCL is exemplified by diffuse large BCL (DLBCL), where gene expression profiling has led to the identification of least two distinct subtypes that are prognostically and mechanistically very different, and which respond differently to treatment. ${ }^{16,17}$ An additional attraction of miRNAs as cancer biomarkers is that they are much more stable than other RNA species and, as a result, can be purified and measured easily in routinely prepared formalin-fixed paraffin-embedded (FFPE) biopsy material ${ }^{18}$ and biological fluids such as blood ${ }^{19}$ (as will be discussed).

The first demonstration that miRNAs could be useful as diagnostic biomarkers came from the 2002 seminal publication of Calin et al, ${ }^{20}$ who made the connection between $13 q 14$, a frequently deleted locus, and downregulation of the $m i R-15 a / 16$ cluster that is encoded within this region in chronic lymphocytic leukemia patients. Two years later, miRNAs were first demonstrated as prognostic biomarkers in lung cancer patients. ${ }^{21}$ Since then, the speed of miRNA cancer biomarker discovery has been quite astonishing, with over 8,500 publications (source: PubMed search [November 17, 2014] string = "[microRNA AND cancer] AND [prognosis OR diagnosis OR biomarker]").

Here, we consider the identity, function, and biomarker potential of miRNAs in BCLs and, most importantly, the hurdles that remain to be overcome if they are really to become part of future clinical practice.

\section{miRNAs and lymphopoiesis}

Potential biomarker miRNAs of lymphomas are by definition aberrantly expressed, but many are also key regulators of lymphopoiesis (and hematopoiesis) (Figure 1 and Table 1).

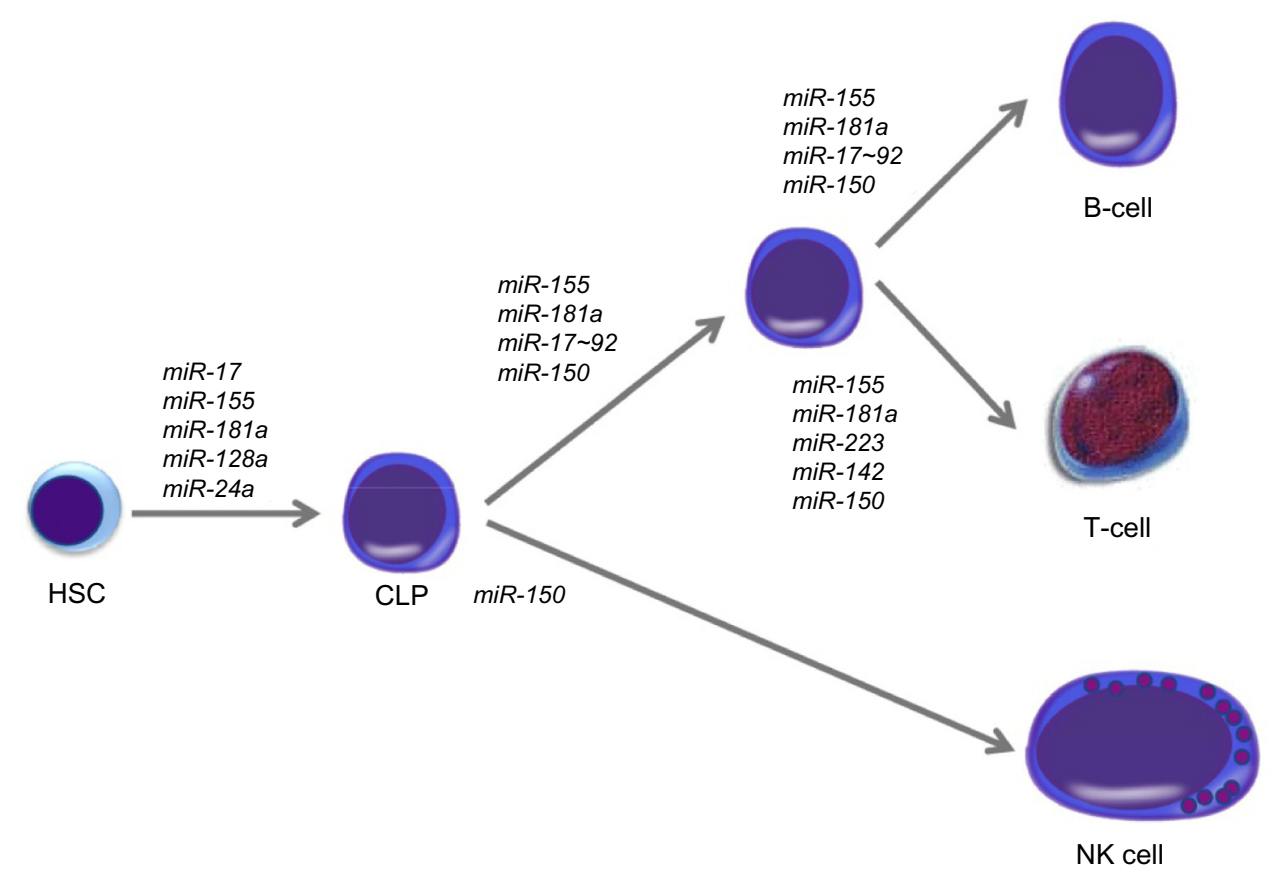

Figure I Role of miRNAs in lymphopoiesis.

Abbreviations: HSC, hematopoietic stem cell; CLP, common lymphoid progenitor; NK, natural killer; miRNA, microRNA. 
Table I Major biomarker miRNAs aberrantly expressed in B-cell lymphomas showing a known role in hematopoiesis and their validated target genes

\begin{tabular}{|c|c|c|c|}
\hline miRNA & Hematopoiesis & Malignancy & Target \\
\hline miR-I55 & B-/T-cell development & DLBCL, BL, AML & 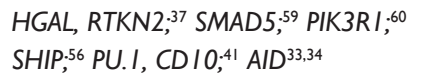 \\
\hline miR-I 7 92 & B-cell development & $\begin{array}{l}\text { B-cell lymphoma, CML, } \\
\text { ALL, MCL }\end{array}$ & $\begin{array}{l}\text { BIM, PTEN:44 E2FI:73 PP2A, PRKAAI;;3-46 } \\
\text { PHLPP2; }{ }^{\prime 18} \text { CCNDII19,120 }\end{array}$ \\
\hline miR-34a & B-cell development & B-cell lymphoma & SIRTI; ${ }^{67}$ MYC; ;21 FOXPI 69 \\
\hline $\operatorname{miR}-125$ & Myelopoiesis & DLBCL, ALL, MDS, AML & IRF4, PRDMI;40 TNFAIP3;42 LIN28A 88 \\
\hline miR-223 & $\begin{array}{l}\text { Myelopoiesis, erythropoiesis, } \\
\text { granulopoiesis, B-cell development }\end{array}$ & MALT, SzS & $\begin{array}{l}\text { MEF2C; }{ }^{\prime 22} L^{2 M O 2 ; 40} \text { NFIA, } \\
\text { CEBPA; }{ }^{123} E 2 A^{97}\end{array}$ \\
\hline miR-I50 & $\begin{array}{l}\text { Myelopoiesis, Megakaryopoiesis, } \\
\text { B-/T-cell development, NK cell development }\end{array}$ & $\begin{array}{l}\text { MDS, MALT, } \\
\text { NK/T-cell lymphoma }\end{array}$ & $\begin{array}{l}\text { MYB; }{ }^{48,124} \text { NOTCH3; } \\
\text { DKCI, AKT2 }\end{array}$ \\
\hline miR-I8I & B-/T-cell development & AML, CLL & $\begin{array}{l}\text { AID, }^{33,34} \text { BCL2, CD69, TCR } \alpha \\
\text { DUSP5, SHP2, PTPN22 }\end{array}$ \\
\hline miR-22 I/222 & Erythropoiesis & & $\mathrm{KIT}^{127}$ \\
\hline miR-I5a/I6-I & & CLL, B-ALL, ALCL & $\begin{array}{l}\text { BCL2, MCLI, CDK6; }{ }^{128} \\
\text { TP53; }{ }^{\prime 29} \text { HIFIA; } ;^{130} \text { CCND I }{ }^{119,120}\end{array}$ \\
\hline miR-2I & & $\begin{array}{l}\text { B-cell lymphoma, } \\
\text { NK/T lymphoma, SzS }\end{array}$ & $\begin{array}{l}\text { PDCD4, PTEN; }{ }^{57} \text { STAT3; }{ }^{\prime 31} \\
\text { ANP32A, SMARCA4 }{ }^{132}\end{array}$ \\
\hline miR-29a & Early HSC development & AML, CLL, MCL & $\mathrm{HBPI} ;{ }^{133} \mathrm{TCLI},{ }^{134}$ \\
\hline $\operatorname{miR}-124 a$ & Myelopoiesis & AML, ALL & EVII , CEBPA, ${ }^{135}$ CDK6 $6^{136}$ \\
\hline
\end{tabular}

Abbreviations: miRNA, microRNA; DLBCL, diffuse large B-cell lymphoma; BL, Burkitt lymphoma; AML, acute myeloid leukemia; CML, chronic myeloid leukemia; CLL, chronic lymphocytic leukemia; ALL, acute lymphoblastic leukemia; MCL, mantle cell lymphoma; MDS, myelodysplastic syndrome; MALT, mucosa-associated lymphoid tissue; SzS, Sézary syndrome; NK, natural killer; B-ALL, B-cell acute lymphoblastic leukemia; ALCL, anaplastic large-cell lymphoma; NK/T, natural killer/T-cell; HSC, hematopoietic stem cell.

In order to fully understand the function of these miRNAs in lymphomagenesis, we must first understand their role under physiological conditions.

Deletion of components of the miRNA biosynthetic pathway in vivo demonstrates the critical role that miRNAs play in hematopoiesis. For example, deletion of Dicer1 resulted in a severe block in peripheral $\mathrm{CD} 8^{+}$development, as well as in reduced numbers of $\mathrm{CD}^{+}$cells which, when stimulated, underwent increased apoptosis and proliferated poorly. ${ }^{22,23}$ However, when Dicer 1 was deleted in $\mathrm{CD} 34^{+}$hematopoietic stem cells (HSCs), this led to an increase in apoptosis coupled with a reduction in hematopoietic ability. ${ }^{24}$ When Dicer 1 was ablated in early B-cell progenitors, the pro- to pre-B-cell transition was blocked as a result of miR-17 92 targeting of BIM, which could be partially rescued by BCL2 expression. ${ }^{25}$ HSCs remain pluripotent while at the same time, they respond to lineage-determining signals in order to differentiate into the various hematopoietic lineages including lymphocytes. This is a finely balanced process tightly controlled by a complex network of extrinsic and intrinsic stimuli, signaling pathways, growth factors, cytokines, transcription factors, and other molecular components. MiRNAs can target many of these factors and, in general, can determine HSC fate, differentiation state and function, the ability to self-renew, apoptosis levels, and the balance of myeloid and lymphoid progenitor cells. ${ }^{26}$ Georgantas et al ${ }^{26}$ identified 33 different
miRNAs commonly expressed in $\mathrm{CD} 34^{+} \mathrm{HSCs}$ derived either from bone marrow or peripheral blood. Using a combination of predictive algorithms as well as functional validation, the authors hypothesized that $m i R-17, m i R-24, m i R-146, m i R-155$, $m i R-128$, and $m i R-181$ act to prevent the differentiation of early-stage progenitors; $m i R-16, m i R-103$, and $m i R-107$ act later on; and $m i R-221, m i R-222$, and $m i R-223$ can control the end stages of hematopoietic development (Figure 1).

The first study to suggest the importance of miRNAs in normal lymphocyte development was performed by Chen et $\mathrm{al}^{27}$ in 2004, who cloned $~ 150$ miRNAs from murine bone marrow and found that $m i R-181, m i R-223$, and $m i R-142$ were preferentially expressed in B-cells. Furthermore, HSCs expressing $m i R-181$ transferred to lethally irradiated mice significantly increased $\mathrm{B}$-cell and cytotoxic $\mathrm{CD} 8^{+} \mathrm{T}$-cell levels. $m i R-181$ can also regulate levels of CD69, BCL2, and T-cell receptor (TCR) $\alpha$ during T-cell development, ${ }^{28}$ and is responsible for TCR sensitivity. ${ }^{29}$ miR-155 deletion in mice made them immunodeficient, with B-cells producing reduced levels of immunoglobulins (Igs) in response to antigen treatment, and T-cells producing lower amounts of interleukin (IL)-2 and interferon gamma. Both of these effects were caused by PU.1 targeting. ${ }^{30,31}$ In vitro activation of B-cells or $\mathrm{CD}^{+} \mathrm{T}$-cells upregulate $m i R-155$, while the deletion of miR-155 in activated B-cells causes a reduction of tumor necrosis factor (TNF) and lymphotoxin by two-thirds of their 
normal levels, and biases T-cell differentiation towards the $\mathrm{T}_{\mathrm{h}} 2$ phenotype. ${ }^{32}$

Both $m i R-155$ and $m i R-181$ are key regulators of germinal center (GC) B-cell differentiation mediated through the targeting of activation-induced cytidine deaminase (AID), an important regulator of B-cell differentiation. ${ }^{33,34}$ The specific deletion of Dicer 1 in activated B-cells dramatically decreased GC B-cell formation and that Dicer-deficient GC B-cells expressed higher levels of BIM. ${ }^{35}$ GC B-cells are defined by the expression of surface proteins including BCL6, CD10, HGAL, and LMO2, and the absence of activated B-cell markers such as PRDM1/BLIMP1 and XBP1. ${ }^{36} \mathrm{MiRNAs}$ can regulate the expression of all these. For instance $m i R-155$ targets both HGAL and Rhotekin $2,{ }^{37}$ the $m i R-30$ family, miR-9 and let-7a, target BCL6 and PRDM1/BLIMP1, ${ }^{38}$ while $m i R-223$ regulates the expression of $\mathrm{LMO} 2,{ }^{39}$ and $m i R-125 \mathrm{~b}$ controls the expression of IRF4 and PRDM1/BLIMP1. ${ }^{40}$ It has also been demonstrated that miR-155 plays a role in activated $\mathrm{B}-\mathrm{cells}$ via nuclear factor-kappa $\mathrm{B}(\mathrm{NF}-\kappa \mathrm{B})$ regulation by the inhibition of PU1 and CD10, ${ }^{41}$ and $m i R-125 a / b$ regulates TNFAIP3 enhancing NF-kB activation. ${ }^{42}$

The miR-17-92 cluster is another important regulator of lymphopoiesis that when deleted blocks pro- to pre-B-cell development via BIM targeting. ${ }^{43}$ In addition members of this cluster can target PP2A, PTEN and AMP-activated kinase (PRKAA1), all important immune regulators. ${ }^{43-46}$ Similar to the miR-17 92 cluster, forced expression of miR-34a in HSCs can inhibit the transition of pro- to pre-B-cells, this time by FOXP1 inhibition, ${ }^{47}$ as does $m i R-150$ expression via MYB downregulation. ${ }^{48}$

\section{Aberrant expression of miRNAs in B-cell lymphomas and their use as biomarkers}

As in normal lymphopoiesis, there is a general requirement for miRNA biosynthetic components in the development and maintenance of BCLs. Deletion of Dicer1 in a MYClymphoma model resulted in the decreased development of lymphoma, and those that did arise were of a very early B-cell precursor stage. ${ }^{49}$ Similarly, in a p53-null model, Dicer 1 deletion reduced lymphomagenesis and conferred prolonged survival to the mice. ${ }^{50}$

\section{Diffuse large B-cell lymphoma (DLBCL)}

DLBCL, the most common form of BCL accounting for nearly $40 \%$ of all lymphoid tumors, ${ }^{51}$ was one of the first cancers to be linked with dysfunctional miRNA expression - namely, the observation of $m i R-155$ overexpression (Figure 2). ${ }^{18,52,53}$
This miRNA is a key "oncomir" in lymphomagenesis, and ectopic expression of $m i R-155$ in mice resulted in the development of a high-grade BCL similar to DLBCL, ${ }^{54}$ with oncogenicity mediated by SHIP1 and C/EBP $\beta$ targeting. ${ }^{55-57}$ Remarkably, when $m i R-155$ overexpression was removed in this model, using either an inducible promoter or antagomir against $m i R-155$, the tumor quickly disappeared, and after 1 week, no detectable disease was found, ${ }^{58}$ demonstrating the potential efficacy of miRNA-based therapeutics against lymphoma. In addition, miR-155 suppresses the in vitro growth-inhibitory effects of TGF- $\beta 1$ and BMP2/4 in DLBCL cells by SMAD5 downregulation, ${ }^{59}$ and it controls PI3K-AKT pathway activity by PIK3R1 targeting. ${ }^{60}$ Furthermore, overexpression of this miRNA promotes TNF $\alpha$-dependent proliferation of DLBCL cells in vivo in xenotransplanted mice. ${ }^{56}$

Recently, it has been demonstrated that SHIP1 is differentially expressed between the two molecular subtypes of DLBCL, GC B-cell-like, and activated B-cell-like (ABC) DLBCL. ${ }^{17}$ This is consistent with previous reports of differences in miR-155 expression levels between ABC- and GC-type DLBCL. ${ }^{18,53}$ Moreover, CD10, indicative of GC-type DLBCL, ${ }^{61}$ and the constitutive expression of NF- $\kappa \mathrm{B}$, a hallmark of ABC-type DLBCL, ${ }^{62}$ are linked via the miR-155/PU.1 regulatory loop. ${ }^{41}$ Interestingly, the lymphoma-inducing herpes viruses, Kaposi's sarcomaassociated herpes virus and Marek's disease virus, encode miR-155 orthologs, ${ }^{63,64}$ whereas Epstein-Barr virus - also intimately involved in lymphomagenesis - can deregulate miR-155 via LMP1 transactivation. ${ }^{65}$

$m i R-34 a$ is a well-described tumor suppressor miRNA that forms part of the p53 network, ${ }^{66}$ with a positive feedback loop between the p53 induction of $m i R-34 a$ expression and activation of p53 by miR-34a through SIRT1 inhibition. ${ }^{67}$ Mice xenotransplanted with U2932 (an ABC-type DLBCL cell line), along with exogenous $m i R-34 a$, had reduced tumor growth - an effect mediated by Foxp 1 targeting, ${ }^{68}$ it is also a molecule that is linked to the high-grade transformation of lymphoma via myc-mediated $m i R-34 a$ repression. ${ }^{69}$

Overexpression of the $m i R-17-92$ cluster in conjunction with MYC accelerates lymphoma development and increases the aggressiveness of tumors ${ }^{70,71}$ due to the presence of a MYC/miR-17-92/E2F circuit in this malignancy. ${ }^{72} \mathrm{MYC}$ upregulates the $m i R-17-92$ cluster which, in turn, inhibits $\mathrm{E} 2 \mathrm{~F} 1$, and E2F3 (pro-proliferative) regulates the $m i R-17-92$ cluster. ${ }^{73}$ Using a E $\mu$-myc murine model, miR-19 was proposed to be the key oncogenic component of the miR-17-92 cluster and was demonstrated to activate the AKT-mTOR 


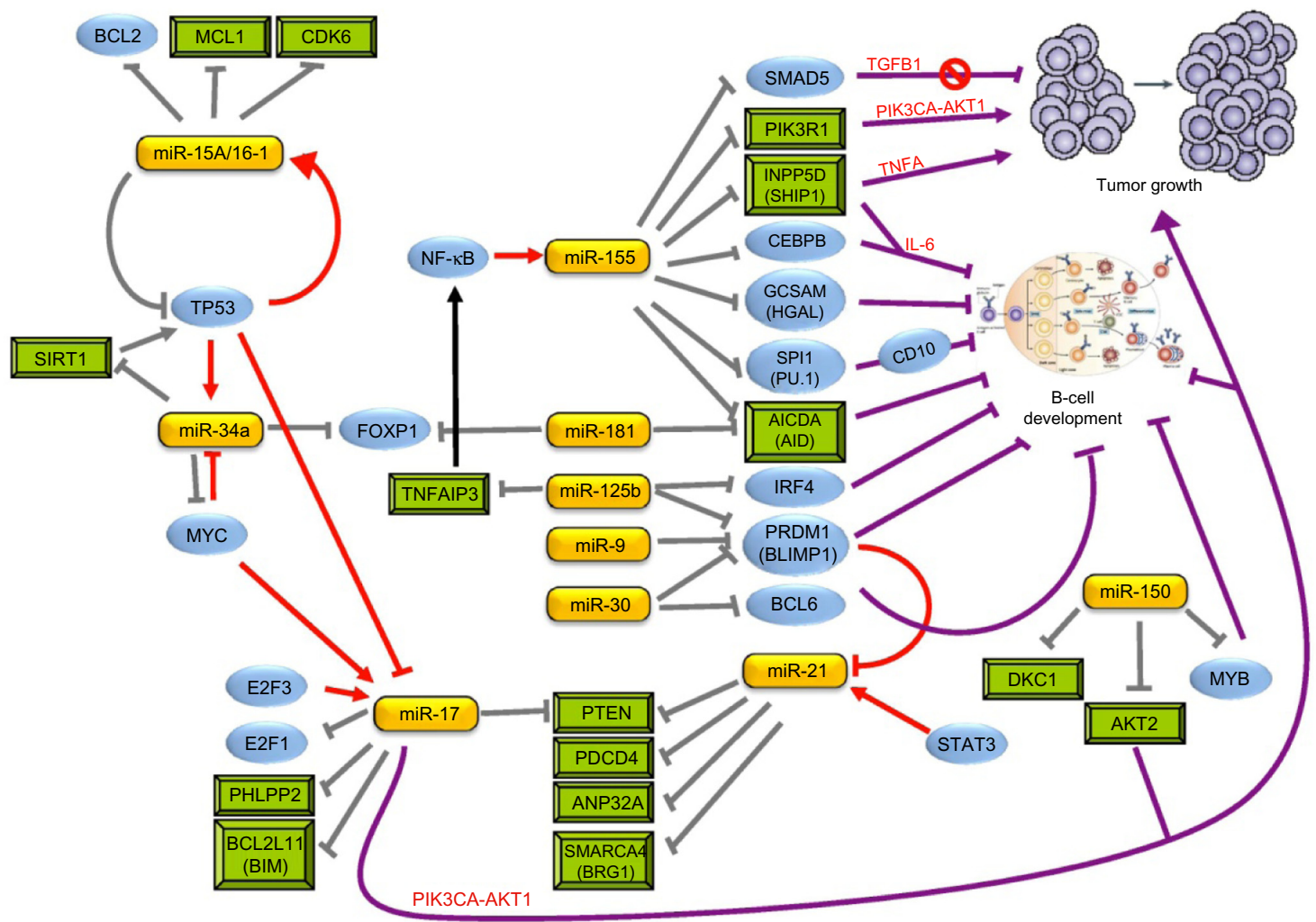

Figure 2 MiRNA involvement in lymphomagenesis.

Notes: Functionally validated target genes of miRNAs are depicted by gray lines, and red lines indicate the transcription factors that are known to regulate the miRNAs. Purple lines show the proposed phenotypic effect of miRNA dysregulation in lymphomagenesis, and the implicated pathways are indicated in red text.

Abbreviations: NF-kB, nuclear factor-kappa B; TNF, tumor necrosis factor; AICDA, activation-induced cytidine deaminase; IL-6, interleukin-6; STAT3, signal transducer and activator of transcription 3; miRNA, microRNA.

pathway via antagonizing PTEN, leading to the promotion of cell survival. ${ }^{74}$

In terms of biomarkers for DLBCL, several early studies linked the expression of miRNAs with the molecular subtypes of DLBCL and prognostic outcomes. ${ }^{18,40,75}$ A retrospective study of 258 DLBCL cases defined a 9-miRNA signature that was independently indicative of both overall survival and progression-free survival in this cohort. ${ }^{76}$ In one study of 176 DLBCL patients uniformly treated with R-CHOP (rituximab, cyclophosphamide, doxorubicin hydrochloride, vincristine sulfate, and prednisone), ${ }^{77}$ levels of $m i R-18 a$ were identified as independent variables associated with overall survival and levels of $m i R-181 a$ and $m i R-222$ with progression-free survival. More recently, a signature of 52 miRNAs was identified in patients with hepatitis $C$ virus-associated DLBCL, and the downregulation of $m i R-138-5 p$ and upregulation of $m i R-147 a, m i R-147 b$, and $m i R-511-5 p$ was correlated with poor prognostic outcomes. ${ }^{78}$

\section{Follicular lymphoma (FL)}

Even though it is the most common type of indolent lymphoma, there are only a few miRNA biomarker studies in FL.
The expression levels of 153 miRNAs were measured in 46 FL samples compared to normal lymph nodes or DLBCL cases. ${ }^{79}$ We identified a 26-miRNA signature that could differentiate between FL cases (number $[n]=18$ ) and de novo cases of DLBCL $(\mathrm{n}=64) .{ }^{75}$ As part of this study, we also found six miRNAs (miR-223, miR-217, miR-222, miR-221, let-7i, and let-7b) that could distinguish FL cases that underwent high-grade histological transformation from those that did not, something not possible by histoimmunochemical means. Other biomarker studies have identified miRNA signatures able to differentiate between FL and nodal marginal zone lymphoma, ${ }^{80}$ and between FL and follicular hyperplasia patients. ${ }^{81}$ The miR-17 92 cluster has been proposed as useful to differentiate between the potentially confounding diagnoses of GC-DLBCL and clinical stage III FL. ${ }^{82}$ Seventeen miRNAs were identified that could distinguish between FL cases harboring the $t(14 ; 18)$ translocation from $t(14 ; 18)$-negative cases (about $10 \%$ of FL cases). Recently, however, a study of 44 FL cases failed to derive a significant miRNA signature that could distinguish between differing subtypes of FL (FL with BCL6 locus rearrangement [FL $\{\mathrm{BCL} 2+/ \mathrm{BCL} 6+\}, \mathrm{FL}\{\mathrm{BCL} 2-/$ BCL6+ $\}$ ] or FL with a diffuse growth pattern). ${ }^{83}$ 


\section{Mantle cell lymphoma (MCL)}

A number of miRNA signatures have now been described for MCL. ${ }^{84-87}$ Overexpression of members of the miR-17 92 cluster, for example, has been associated with high MYC levels in aggressive MCL, ${ }^{86}$ and inhibition of chemotherapyinduced apoptosis in MCL cell lines, ${ }^{88}$ while downregulation of $m i R-29$ has been proposed as a potential prognostic marker for this malignancy. ${ }^{84}$

\section{Burkitt lymphoma (BL)}

Mice carrying mutations in the $3^{\prime}$-UTR miR-155 binding site of AID contain increased levels of MYC-IgH (t[8;14]) translocations - the characteristic genetic hallmark of Burkitt lymphoma (BL). ${ }^{89}$ Although the three major subtypes of BL (sporadic, endemic, and HIV-associated) share a very similar miRNA profile, all three were shown to be distinct from DLBCL. ${ }^{90}$ Although $m i R-155$ is overexpressed in pediatric cases, ${ }^{91}$ in adult BL cases, this does not appear to be the case. $^{52,92,93}$

\section{Other B-cell lymphomas}

In Hodgkin lymphoma (HL), low miR-135a levels have been associated with poorer prognostic outcomes. ${ }^{94,95}$ Mucosa-associated lymphoid tissue (MALT) lymphoma has been distinguished from gastric DLBCL, a potentially difficult differential diagnosis by a 27 -miRNA signature. ${ }^{69}$ In another study, five miRNAs ( $m i R-150, m i R-550, m i R-124 a$, $m i R-518 b$, and $m i R-539)$ were proposed to be able to distinguish between gastritis and MALT lymphoma, ${ }^{96}$ and in another study, miR-223 levels correlated with increased E2A expression in MALT lymphoma. ${ }^{97}$ Bouteloup et $\mathrm{a}^{98}$ analyzed 15 splenic marginal zone lymphoma (SMZL) cases by microarray and reported eight miRNAs including $m i R-21$ that distinguished between aggressive $(n=2)$ and indolent $(n=4)$ cases of SMZL. More recently, purified B-cell populations from 31 cases of SMZL were differentiated from the spleens of reactive lymphoid hyperplasia, and spleens from patients with other BCLs by a 51-miRNA signature. ${ }^{99}$

\section{miRNAs as noninvasive biomarkers of B-cell lymphoma}

The standard protocol for the diagnosis of lymphoma (and other cancers) remains the histopathological review of tumor material obtained by invasive biopsy - a procedure that is typically expensive, uncomfortable, and sometimes risky for patients. Therefore, there has been great interest in the field of circulating nucleic acids in plasma and serum as noninvasive cancer biomarkers. ${ }^{100,101}$ An additional benefit of blood-based testing is the ability to carry out screening and repeat sampling on patients undergoing therapy, or monitoring disease progression allowing for the development of a personalized approach to cancer patient management.

Unlike other RNA classes, the vast majority of which are degraded by high levels of RNases found in the blood, ${ }^{102}$ miRNAs appear stable in the blood and are surprisingly resistant to fragmentation by either chemical or enzymatic agents. ${ }^{103}$ In 2007, we first reported the presence of miRNAs in the blood of cancer (lymphoma) patients, ${ }^{104}$ and in 2008 observed the upregulation of $m i R-155$ and $m i R-210$ in the blood (sera) of DLBCL patients compared to healthy controls and the prognostic potential of $m i R-21^{105}$ - an observation validated independently some years later. ${ }^{106}$ As well as confirming the upregulation of $m i R-155$ in DLBCL sera, a recent study additionally reported the upregulation of $m i R-15 a, m i R$ 16 , and $m i R-29 c$ and downregulation of $m i R-34 a \cdot{ }^{107} \mathrm{~A}$ further study, this time in plasma rather than sera, observed reduced levels of $m i R-92$ that varied in response to chemotherapy in DLBCL, FL, and T-cell non-HL patients. ${ }^{108}$ In HL patient plasma, $m i R-494$ and $m i R-1973$ were identified as indicators of both relapse and interim therapy response. ${ }^{109}$ Plasma miR221 has been found to be a good diagnostic and prognostic marker for extranodal natural killer T-cell lymphoma. ${ }^{110}$ Clearly, although the results are very preliminary, the ability of miRNAs to act as noninvasive biomarkers of BCLs is a promising prospect.

\section{Summary and future directions}

The identification of miRNAs that are aberrantly expressed in tumor cells compared to their respective normal counterpart cells was the initial goal of many early miRNA studies. ${ }^{13,111}$ However, although of great scientific interest, this approach has limited diagnostic utility, as studies are almost exclusively retrospective and based upon the ability to confirm previously made clinical diagnoses. Much more useful is the ability of miRNAs to differentiate between diagnoses of benign and malignant conditions, between confounding pathologies, and to confirm or add to the molecular classification of tumors, which is often limited by the prerequisite for fresh or frozen material. For example, the miR-17 92 cluster has been suggested as a useful diagnostic differentiator between the potentially conflicting diagnostic classifications of GC-DLBCL and grade $3 \mathrm{FL}$ cases. ${ }^{82}$ In addition to facilitating diagnosis, one of the most clinically useful features of miRNAs is their potential as prognostic biomarkers. This can be a result of acting as a surrogate marker of a previously recognized prognostic marker (eg, clinical, cytogenetic, or molecular) 
or as an independent prognosticator. The majority of studies to date fall within the former category. For example, Calin et $\mathrm{al}^{112}$ identified a 13-miRNA signature on the basis of comparisons between chronic lymphocyte leukemia groups with typically good outcomes (low ZAP70, mutated $\operatorname{IgH}$ ) with those with a typically poor outcome (high ZAP70, unmutated $\operatorname{IgH})$. In the latter category, a miRNA signature was derived that could predict prognostic outcome independently of other chromosomal or clinical parameters in DLBCL patients treated with R-CHOP. ${ }^{77}$

There has been a great deal of interest in the use of miRNAs as indicators of response to treatment in solid tumors. ${ }^{113}$ We identified $m i R-27 a$ as being important in bortezomib action in myeloma, ${ }^{114}$ whereas $m i R-125 b$ is the main determinant of sensitivity in cutaneous T-cell lymphoma. ${ }^{115}$ In HL, $m i R-21$ and $m i R$-30d were demonstrated to be responsible for doxorubicin-induced apoptosis, although normally this drug is only used as part of combination therapy. ${ }^{116}$

The miRNA BCL biomarker studies described here are by no means an exhaustive list, but are instead intended to illustrate the rapid growth of the field. An especially useful characteristic of miRNAs as biomarkers is their remarkable stability, which means that they can be robustly measured from routine FFPE biopsy material. ${ }^{18}$ Consequently, retrospective miRNA studies can be carried out on the huge collections of pathology laboratories worldwide, something that is not feasible when investigating traditional genes. Indeed, most miRNA studies have been carried out on FFPE material, and this characteristic has greatly facilitated the rapid pace of discovery of miRNA involvement in all but the rarest of malignant pathologies. Another attractive feature of miRNAs as biomarkers is the ability to detect these molecules in biological fluids including blood, tears, urine, saliva, amniotic fluid, breast milk, cerebrospinal fluid, and seminal fluid, ${ }^{117}$ offering the possibility of noninvasive cancer biomarkers that could be used for monitoring disease progression and treatment response.

However, it should be noted that the vast majority of miRNA biomarker studies to date are single-center and retrospective. Consequently, the reliability of much of these data remains contentious and should be treated with some caution, as the degree of discordancy between seemingly identical studies is troubling and, in reality, very few of the biomarker studies published will ever make it into clinical practice. These differences are primarily due to biological and technical variation between the studies, such as the starting material used in experiments (eg, the purification of cells, cell types, the control populations used, RNA extraction, etc), as well as the technological platforms (eg, microarray, quantitative real-time reverse transcription polymerase chain reaction, versus next-generation sequencing, etc) and differing statistical methodologies used. Consequently, there is a clear need for a standardized approach to be taken in future miRNA biomarker studies in order to rationalize these confounding factors. In particular, a systematic approach should be taken in a similar fashion to that achieved for other "omic" disciplines (ie, transcriptomics and genomics).

\section{Acknowledgments}

We apologize to the authors of the many studies that were not included in this review due to space limitations. CHL and his research are supported by funding from the Starmer-Smith memorial lymphoma fund, and Ikerbasque, the Basque Foundation for Science. MFM and IG are supported by the Asociación Española Contra el Cáncer (AECC).

\section{Disclosure}

The authors report no conflicts of interest in this work.

\section{References}

1. Crick F. Central dogma of molecular biology. Nature. 1970;227(5258): 561-563.

2. Mattick JS. Non-coding RNAs: the architects of eukaryotic complexity. EMBO Rep. 2001;2(11):986-991.

3. Wightman B, Ha I, Ruvkun G. Posttranscriptional regulation of the heterochronic gene lin-14 by lin- 4 mediates temporal pattern formation in C. elegans. Cell. 1993;75(5):855-862.

4. Lee RC, Feinbaum RL, Ambros V. The C. elegans heterochronic gene lin-4 encodes small RNAs with antisense complementarity to lin-14. Cell. 1993;75(5):843-854.

5. Lee RC, Ambros V. An extensive class of small RNAs in Caenorhabditis elegans. Science. 2001;294(5543):862-864.

6. Griffiths-Jones S, Grocock RJ, van Dongen S, Bateman A, Enright AJ. miRBase: microRNA sequences, targets and gene nomenclature. Nucleic Acids Res. 2006;34(Database issue):D140-D144.

7. Friedman RC, Farh KK, Burge CB, Bartel DP. Most mammalian mRNAs are conserved targets of microRNAs. Genome Res. 2009;19(1): 92-105.

8. Kim VN. MicroRNA biogenesis: coordinated cropping and dicing. Nat Rev Mol Cell Biol. 2005;6(5):376-385.

9. Calin GA, Sevignani C, Dumitru CD, et al. Human microRNA genes are frequently located at fragile sites and genomic regions involved in cancers. Proc Natl Acad Sci U S A. 2004;101(9):2999-3004.

10. Lawrie $\mathrm{CH}$. MicroRNA expression in lymphoid malignancies: new hope for diagnosis and therapy? J Cell Mol Med. 2008;12(5A):1432-1444.

11. Iorio MV, Croce CM. MicroRNAs in cancer: small molecules with a huge impact. J Clin Oncol. 2009;27(34):5848-5856.

12. Croce CM. Causes and consequences of microRNA dysregulation in cancer. Nat Rev Genet. 2009;10(10):704-714.

13. Lu J, Getz G, Miska EA, et al. MicroRNA expression profiles classify human cancers. Nature. 2005;435(7043):834-838.

14. Swerdlow S, Campo E, Lee Harris N, et al, editors. WHO Classification of Tumours of the Haematopoietic and Lymphoid Tissue. 4th ed. Lyon, France: International Agency for Research on Cancer; 2008.

15. Connors JM. Non-Hodgkin lymphoma: the clinician's perspective - a view from the receiving end. Mod Pathol. 2013;26 Suppl 1: S111-S118. 
16. Lenz G, Davis RE, NgoVN, et al. Oncogenic CARD11 mutations in human diffuse large B cell lymphoma. Science. 2008;319(5870):1676-1679.

17. Alizadeh AA, Eisen MB, Davis RE, et al. Distinct types of diffuse large B-cell lymphoma identified by gene expression profiling. Nature. 2000;403(6769):503-511.

18. Lawrie $\mathrm{CH}$, Soneji S, Marafioti T, et al. MicroRNA expression distinguishes between germinal center B cell-like and activated B cell-like subtypes of diffuse large B cell lymphoma. Int J Cancer. 2007;121(5): $1156-1161$.

19. Lawrie $\mathrm{CH}$, Larrea E, Larrinaga $\mathrm{G}$, et al. Targeted next-generation sequencing and non-coding RNA expression analysis of clear cell papillary renal cell carcinoma suggests distinct pathological mechanisms from other renal tumour subtypes. $J$ Pathol. 2014;232(1):32-42.

20. Calin GA, Dumitru CD, Shimizu M, et al. Frequent deletions and down-regulation of micro- RNA genes miR15 and miR16 at 13q14 in chronic lymphocytic leukemia. Proc Natl Acad Sci U SA. 2002;99(24): 15524-15529.

21. Takamizawa J, Konishi H, Yanagisawa K, et al. Reduced expression of the let-7 microRNAs in human lung cancers in association with shortened postoperative survival. Cancer Res. 2004;64(11):3753-3756.

22. Cobb BS, Nesterova TB, Thompson E, et al. T cell lineage choice and differentiation in the absence of the RNase III enzyme Dicer. $J$ Exp Med. 2005;201(9):1367-1373.

23. Muljo SA, Ansel KM, Kanellopoulou C, Livingston DM, Rao A, Rajewsky K. Aberrant T cell differentiation in the absence of Dicer. J Exp Med. 2005;202(2):261-269.

24. Guo S, Lu J, Schlanger R, et al. MicroRNA miR-125a controls hematopoietic stem cell number. Proc Natl Acad Sci U S A. 2010;107(32):14229-14234.

25. Koralov SB, Muljo SA, Galler GR, et al. Dicer ablation affects antibody diversity and cell survival in the B lymphocyte lineage. Cell. 2008;132(5):860-874

26. Georgantas RW 3rd, Hildreth R, Morisot S, et al. CD34+ hematopoietic stem-progenitor cell microRNA expression and function: a circuit diagram of differentiation control. Proc Natl Acad Sci U SA. 2007;104(8): 2750-2755.

27. Chen CZ, Li L, Lodish HF, Bartel DP. MicroRNAs modulate hematopoietic lineage differentiation. Science. 2004;303(5654):83-86.

28. Neilson JR, Zheng GX, Burge CB, Sharp PA. Dynamic regulation of miRNA expression in ordered stages of cellular development. Genes Dev. 2007;21(5):578-589.

29. Li QJ, Chau J, Ebert PJ, et al. miR-181a is an intrinsic modulator of T cell sensitivity and selection. Cell. 2007;129(1):147-161.

30. Rodriguez A, Vigorito E, Clare S, et al. Requirement of bic/microRNA155 for normal immune function. Science. 2007;316(5824):608-611.

31. Thai TH, Calado DP, Casola S, et al. Regulation of the germinal center response by microRNA-155. Science. 2007;316(5824):604-608.

32. Vigorito E, Perks KL, Abreu-Goodger C, et al. microRNA-155 regulates the generation of immunoglobulin class-switched plasma cells. Immunity. 2007;27(6):847-859.

33. de Yébenes VG, Belver L, Pisano DG, et al. miR-181b negatively regulates activation-induced cytidine deaminase in B cells. J Exp Med. 2008;205(10):2199-2206.

34. Teng G, Hakimpour P, Landgraf P, et al. MicroRNA-155 is a negative regulator of activation-induced cytidine deaminase. Immunity. 2008;28(5):621-629.

35. Xu S, Guo K, Zeng Q, Huo J, Lam KP. The RNase III enzyme Dicer is essential for germinal center B-cell formation. Blood. 2012;119(3): 767-776.

36. Choi WW, Weisenburger DD, Greiner TC, et al. A new immunostain algorithm classifies diffuse large B-cell lymphoma into molecular subtypes with high accuracy. Clin Cancer Res. 2009;15(17): 5494-5502.

37. Dagan LN, Jiang X, Bhatt S, Cubedo E, Rajewsky K, Lossos IS. miR155 regulates HGAL expression and increases lymphoma cell motility. Blood. 2012;119(2):513-520.
38. Lin J, Lwin T, Zhao JJ, et al. Follicular dendritic cell-induced microRNA-mediated upregulation of PRDM1 and downregulation of BCL-6 in non-Hodgkin's B-cell lymphomas. Leukemia. 2011;25(1): $145-152$.

39. Gururajan M, Haga CL, Das S, et al. MicroRNA 125b inhibition of B cell differentiation in germinal centers. Int Immunol. 2010;22(7):583-592.

40. Malumbres R, Sarosiek KA, Cubedo E, et al. Differentiation stagespecific expression of microRNAs in B lymphocytes and diffuse large B-cell lymphomas. Blood. 2009;113(16):3754-3764.

41. Thompson RC, Herscovitch M, Zhao I, Ford TJ, Gilmore TD. NF-kappaB down-regulates expression of the B-lymphoma marker CD10 through a miR-155/PU.1 pathway. J Biol Chem. 2011;286(3):1675-1682.

42. Kim SW, Ramasamy K, Bouamar H, Lin AP, Jiang D, Aguiar RC. MicroRNAs miR-125a and miR-125b constitutively activate the NF- $\kappa \mathrm{B}$ pathway by targeting the tumor necrosis factor alpha-induced protein 3 (TNFAIP3, A20). Proc Natl Acad Sci U S A. 2012;109(20): 7865-7870.

43. Ventura A, Young AG, Winslow MM, et al. Targeted deletion reveals essential and overlapping functions of the miR-17 through 92 family of miRNA clusters. Cell. 2008;132(5):875-886.

44. Xiao C, Srinivasan L, Calado DP, et al. Lymphoproliferative disease and autoimmunity in mice with increased miR-17-92 expression in lymphocytes. Nat Immunol. 2008;9(4):405-414.

45. Mu P, Han YC, Betel D, et al. Genetic dissection of the miR-17 92 cluster of microRNAs in Myc-induced B-cell lymphomas. Genes Dev. 2009;23(24):2806-2811.

46. Mavrakis KJ, Wolfe AL, Oricchio E, et al. Genome-wide RNA-mediated interference screen identifies miR-19 targets in Notch-induced T-cell acute lymphoblastic leukaemia. Nat Cell Biol. 2010;12(4): 372-379.

47. Rao DS, O'Connell RM, Chaudhuri AA, Garcia-Flores Y, Geiger TL, Baltimore D. MicroRNA-34a perturbs B lymphocyte development by repressing the forkhead box transcription factor Foxp1. Immunity. 2010;33(1):48-59.

48. Zhou B, Wang S, Mayr C, Bartel DP, Lodish HF. miR-150, a microRNA expressed in mature B and T cells, blocks early B cell development when expressed prematurely. Proc Natl Acad Sci U SA. 2007;104(17): 7080-7085.

49. Arrate MP, Vincent T, Odvody J, Kar R, Jones SN, Eischen CM. MicroRNA biogenesis is required for Myc-induced B-cell lymphoma development and survival. Cancer Res. 2010;70(14):6083-6092.

50. Adams CM, Eischen CM. Inactivation of p53 is insufficient to allow $\mathrm{B}$ cells and B-cell lymphomas to survive without Dicer. Cancer Res. 2014;74(14):3923-3934.

51. Coiffier B. Diffuse large cell lymphoma. Curr Opin Oncol. 2001;13(5): 325-334.

52. Kluiver J, Poppema S, de Jong D, et al. BIC and miR-155 are highly expressed in Hodgkin, primary mediastinal and diffuse large B cell lymphomas. J Pathol. 2005;207(2):243-249.

53. Eis PS, Tam W, Sun L, et al. Accumulation of miR-155 and BIC RNA in human B cell lymphomas. Proc Natl Acad Sci U SA. 2005;102(10): $3627-3632$

54. Costinean S, Zanesi N, Pekarsky Y, et al. Pre-B cell proliferation and lymphoblastic leukemia/high-grade lymphoma in $\mathrm{E}(\mathrm{mu})$-miR 155 transgenic mice. Proc Natl Acad Sci U S A. 2006;103(18):7024-7029.

55. O'Connell RM, Chaudhuri AA, Rao DS, Baltimore D. Inositol phosphatase SHIP1 is a primary target of miR-155. Proc Natl Acad Sci USA. 2009;106(17):7113-7118.

56. Pedersen IM, Otero D, Kao E, et al. Onco-miR-155 targets SHIP1 to promote TNFalpha-dependent growth of B cell lymphomas. EMBO Mol Med. 2009;1(5):288-295.

57. Yamanaka Y, Tagawa H, Takahashi N, et al. Aberrant overexpression of microRNAs activate AKT signaling via down-regulation of tumor suppressors in natural killer-cell lymphoma/leukemia. Blood. 2009;114(15):3265-3275 
58. Babar IA, Cheng CJ, Booth CJ, et al. Nanoparticle-based therapy in an in vivo microRNA-155 (miR-155)-dependent mouse model of lymphoma. Proc Natl Acad Sci U S A. 2012;109(26):E1695-E1704.

59. Rai D, Kim SW, McKeller MR, Dahia PL, Aguiar RC. Targeting of SMAD5 links microRNA-155 to the TGF-beta pathway and lymphomagenesis. Proc Natl Acad Sci U S A. 2010;107(7):3111-3116.

60. Huang X, Shen Y, Liu M, et al. Quantitative proteomics reveals that miR-155 regulates the PI3K-AKT pathway in diffuse large B-cell lymphoma. Am J Pathol. 2012;181(1):26-33.

61. Hans CP, Weisenburger DD, Greiner TC, et al. Confirmation of the molecular classification of diffuse large B-cell lymphoma by immunohistochemistry using a tissue microarray. Blood. 2004;103(1):275-282.

62. Compagno M, Lim WK, Grunn A, et al. Mutations of multiple genes cause deregulation of NF-kappaB in diffuse large B-cell lymphoma. Nature. 2009;459(7247):717-721.

63. Gottwein E, Mukherjee N, Sachse C, et al. A viral microRNA functions as an orthologue of cellular miR-155. Nature. 2007;450(7172): 1096-1099.

64. Zhao Y, Xu H, Yao Y, et al. Critical role of the virus-encoded microRNA-155 ortholog in the induction of Marek's disease lymphomas. PLoS Pathog. 2011;7(2):e1001305.

65. Gatto G, Rossi A, Rossi D, Kroening S, Bonatti S, Mallardo M. EpsteinBarr virus latent membrane protein 1 trans-activates miR-155 transcription through the NF-kappaB pathway. Nucleic Acids Res. 2008;36(20): 6608-6619.

66. He L, He X, Lim LP, et al. A microRNA component of the p53 tumour suppressor network. Nature. 2007;447(7148):1130-1134.

67. Yamakuchi M, Lowenstein CJ. MiR-34, SIRT1 and p53: the feedback loop. Cell Cycle. 2009;8(5):712-715.

68. Craig VJ, Tzankov A, Flori M, Schmid CA, Bader AG, Müller A Systemic microRNA-34a delivery induces apoptosis and abrogates growth of diffuse large B-cell lymphoma in vivo. Leukemia. 2012;26(11):2421-2424

69. Craig VJ, Cogliatti SB, Imig J, et al. Myc-mediated repression of microRNA-34a promotes high-grade transformation of B-cell lymphoma by dysregulation of FoxP1. Blood. 2011;117(23): 6227-6236.

70. He L, Thomson JM, Hemann MT, et al. A microRNA polycistron as a potential human oncogene. Nature. 2005;435(7043):828-833.

71. Tagawa H, Karube K, Tsuzuki S, Ohshima K, Seto M. Synergistic action of the microRNA-17 polycistron and Myc in aggressive cancer development. Cancer Sci. 2007;98(9):1482-1490.

72. O’Donnell KA, Wentzel EA, Zeller KI, Dang CV, Mendell JT. c-Myc-regulated microRNAs modulate E2F1 expression. Nature. 2005;435(7043):839-843.

73. Woods K, Thomson JM, Hammond SM. Direct regulation of an oncogenic micro-RNA cluster by E2F transcription factors. J Biol Chem. 2007;282(4):2130-2134

74. Olive V, Bennett MJ, Walker JC, et al. miR-19 is a key oncogenic component of mir-17-92. Genes Dev. 2009;23(24):2839-2849.

75. Lawrie $\mathrm{CH}$, Chi J, Taylor S, et al. Expression of microRNAs in diffuse large B cell lymphoma is associated with immunophenotype, survival and transformation from follicular lymphoma. J Cell Mol Med. 2009;13(7):1248-1260.

76. Montes-Moreno S, Martinez N, Sanchez-Espiridión B, et al. miRNA expression in diffuse large B-cell lymphoma treated with chemoimmunotherapy. Blood. 2011;118(4):1034-1040.

77. Alencar AJ, Malumbres R, Kozloski GA, et al. MicroRNAs are independent predictors of outcome in diffuse large B-cell lymphoma patients treated with R-CHOP. Clin Cancer Res. 2011;17(12):4125-4135.

78. Augello C, Gianelli U, Savi F, et al. MicroRNA as potential biomarker in HCV-associated diffuse large B-cell lymphoma. J Clin Pathol. 2014;67(8):697-701.

79. Roehle A, Hoefig KP, Repsilber D, et al. MicroRNA signatures characterize diffuse large B-cell lymphomas and follicular lymphomas. $\mathrm{Br}$ J Haematol. 2008;142(5):732-744.
80. Arribas AJ, Campos-Martín Y, Gómez-Abad C, et al. Nodal marginal zone lymphoma: gene expression and miRNA profiling identify diagnostic markers and potential therapeutic targets. Blood. 2012;119(3): e9-e21.

81. Wang W, Corrigan-Cummins M, Hudson J, et al. MicroRNA profiling of follicular lymphoma identifies microRNAs related to cell proliferation and tumor response. Haematologica. 2012;97(4):586-594.

82. Fassina A, Marino F, Siri M, et al. The miR-17-92 microRNA cluster: a novel diagnostic tool in large B-cell malignancies. Lab Invest. 2012;92(11):1574-1582.

83. Gebauer N, Gollub W, Stassek B, et al. MicroRNA signatures in subtypes of follicular lymphoma. Anticancer Res. 2014;34(5):2105-2111.

84. Zhao JJ, Lin J, Lwin T, et al. microRNA expression profile and identification of miR-29 as a prognostic marker and pathogenetic factor by targeting CDK6 in mantle cell lymphoma. Blood. 2010;115(13): 2630-2639.

85. Di Lisio L, Gómez-López G, Sánchez-Beato M, et al. Mantle cell lymphoma: transcriptional regulation by microRNAs. Leukemia. 2010;24(7):1335-1342.

86. Navarro A, Beà S, Fernández V, et al. MicroRNA expression, chromosomal alterations, and immunoglobulin variable heavy chain hypermutations in Mantle cell lymphomas. Cancer Res. 2009;69(17): 7071-7078.

87. Iqbal J, Shen Y, Liu Y, et al. Genome-wide miRNA profiling of mantle cell lymphoma reveals a distinct subgroup with poor prognosis. Blood. 2012;119(21):4939-4948.

88. Chaudhuri AA, So AY, Mehta A, et al. Oncomir miR-125b regulates hematopoiesis by targeting the gene Lin28A. Proc Natl Acad Sci USA. 2012;109(11):4233-4238.

89. Dorsett Y, McBride KM, Jankovic M, et al. MicroRNA-155 suppresses activation-induced cytidine deaminase-mediated Myc-Igh translocation. Immunity. 2008;28(5):630-638.

90. Lenze D, Leoncini L, Hummel M, et al. The different epidemiologic subtypes of Burkitt lymphoma share a homogenous micro RNA profile distinct from diffuse large B-cell lymphoma. Leukemia. 2011;25(12):1869-1876

91. Metzler M, Wilda M, Busch K, Viehmann S, Borkhardt A. High expression of precursor microRNA-155/BIC RNA in children with Burkitt lymphoma. Genes Chromosomes Cancer. 2004;39(2) 167-169.

92. Kluiver J, Haralambieva E, de Jong D, et al. Lack of BIC and microRNA miR-155 expression in primary cases of Burkitt lymphoma. Genes Chromosomes Cancer. 2006;45(2):147-153.

93. van den Berg A, Kroesen BJ, Kooistra K, et al. High expression of B-cell receptor inducible gene BIC in all subtypes of Hodgkin lymphoma. Genes Chromosomes Cancer. 2003;37(1):20-28.

94. Nie K, Gomez M, Landgraf P, et al. MicroRNA-mediated downregulation of PRDM1/Blimp-1 in Hodgkin/Reed-Sternberg cells: a potential pathogenetic lesion in Hodgkin lymphomas. Am J Pathol. 2008;173(1):242-252.

95. Navarro A, Gaya A, Martinez A, et al. MicroRNA expression profiling in classic Hodgkin lymphoma. Blood. 2008;111(5):2825-2832.

96. Thorns C, Kuba J, Bernard V, et al. Deregulation of a distinct set of microRNAs is associated with transformation of gastritis into MALT lymphoma. Virchows Arch. 2012;460(4):371-377.

97. Liu TY, Chen SU, Kuo SH, Cheng AL, Lin CW. E2A-positive gastric MALT lymphoma has weaker plasmacytoid infiltrates and stronger expression of the memory B-cell-associated miR-223: possible correlation with stage and treatment response. Mod Pathol. 2010;23(11): 1507-1517.

98. Bouteloup M, Verney A, Rachinel N, et al. MicroRNA expression profile in splenic marginal zone lymphoma. Br J Haematol. 2012;156(2): 279-281.

99. Arribas AJ, Gómez-Abad C, Sánchez-Beato M, et al. Splenic marginal zone lymphoma: comprehensive analysis of gene expression and miRNA profiling. Mod Pathol. 2013;26(7):889-901. 
100. Pathak AK, Bhutani M, Kumar S, Mohan A, Guleria R. Circulating cell-free DNA in plasma/serum of lung cancer patients as a potential screening and prognostic tool. Clin Chem. 2006;52(10):1833-1842.

101. Anker P, Mulcahy H, Stroun M. Circulating nucleic acids in plasma and serum as a noninvasive investigation for cancer: time for largescale clinical studies? Int J Cancer. 2003;103(2):149-152.

102. Duttagupta R, Jiang R, Gollub J, Getts RC, Jones KW. Impact of cellular miRNAs on circulating miRNA biomarker signatures. PLoS One. 2011;6(6):e20769.

103. Mitchell PS, Parkin RK, Kroh EM, et al. Circulating microRNAs as stable blood-based markers for cancer detection. Proc Natl Acad Sci U S A. 2008;105(30):10513-10518.

104. Lawrie CH. MicroRNA expression in lymphoma. Expert Opin Biol Ther. 2007;7(9):1363-1374.

105. Lawrie CH, Gal S, Dunlop HM, et al. Detection of elevated levels of tumour-associated microRNAs in serum of patients with diffuse large B-cell lymphoma. Br J Haematol. 2008;141(5):672-675.

106. Chen $\mathrm{W}$, Wang $\mathrm{H}$, Chen $\mathrm{H}$, et al. Clinical significance and detection of microRNA-21 in serum of patients with diffuse large B-cell lymphoma in Chinese population. Eur J Haematol. 2014;92(5):407-412.

107. Fang C, Zhu DX, Dong HJ, et al. Serum microRNAs are promising novel biomarkers for diffuse large B cell lymphoma. Ann Hematol. 2012;91(4):553-559.

108. Ohyashiki K, Umezu T, Yoshizawa S, et al. Clinical impact of downregulated plasma miR-92a levels in non-Hodgkin's lymphoma. PLoS One. 2011;6(2):e16408.

109. Jones K, Nourse JP, Keane C, Bhatnagar A, Gandhi MK. Plasma microRNA are disease response biomarkers in classical Hodgkin lymphoma. Clin Cancer Res. 2014;20(1):253-264.

110. Guo HQ, Huang GL, Guo CC, Pu XX, Lin TY. Diagnostic and prognostic value of circulating miR-221 for extranodal natural killer/T-cell lymphoma. Dis Markers. 2010;29(5):251-258.

111. Lawrie CH, Saunders NJ, Soneji S, et al. MicroRNA expression in lymphocyte development and malignancy. Leukemia. 2008;22(7): 1440-1446.

112. Calin GA, Ferracin M, Cimmino A, et al. A MicroRNA signature associated with prognosis and progression in chronic lymphocytic leukemia. $N$ Engl J Med. 2005;353(17):1793-1801.

113. Giovannetti E, Erozenci A, Smit J, Danesi R, Peters GJ. Molecular mechanisms underlying the role of microRNAs (miRNAs) in anticancer drug resistance and implications for clinical practice. Crit Rev Oncol Hematol. 2012;81(2):103-122.

114. Ballabio E, Armesto $\mathrm{M}$, Breeze $\mathrm{CE}$, et al. Bortezomib action in multiple myeloma: microRNA-mediated synergy (and miR-27a/CDK5 driven sensitivity)? Blood Cancer J. 2012;2:e83.

115. Manfè V, Biskup E, Willumsgaard A, et al. cMyc/miR-125b-5p signalling determines sensitivity to bortezomib in preclinical model of cutaneous T-cell lymphomas. PLoS One. 2013;8(3):e59390.

116. Sánchez-Espiridión B, Martín-Moreno AM, Montalbán C, et al. MicroRNA signatures and treatment response in patients with advanced classical Hodgkin lymphoma. Br J Haematol. 2013;162(3): 336-347.

117. Weber JA, Baxter DH, Zhang S, et al. The microRNA spectrum in 12 body fluids. Clin Chem. 2010;56(11):1733-1741.

118. Rao E, Jiang C, Ji M, et al. The miRNA-17-92 cluster mediates chemoresistance and enhances tumor growth in mantle cell lymphoma via PI3K/AKT pathway activation. Leukemia. 2012;26(5):1064-1072.

Blood and Lymphatic Cancer: Targets and Therapy

\section{Publish your work in this journal}

Blood and Lymphatic Cancer: Targets and Therapy is an international, peer-reviewed, open access journal focusing on blood and lymphatic cancer research, identification of therapeutic targets and the optimal use of preventative and integrated treatment interventions to achieve improved outcomes, enhanced survival and quality of life for the
119. Chen RW, Bemis LT, Amato CM, et al. Truncation in CCND1 mRNA alters miR-16-1 regulation in mantle cell lymphoma. Blood. 2008;112(3):822-829.

120. Deshpande A, Pastore A, Deshpande AJ, et al. 3’UTR mediated regulation of the cyclin D1 proto-oncogene. Cell Cycle. 2009;8(21): 3592-3600.

121. Sotillo E, Laver T, Mellert H, et al. Myc overexpression brings out unexpected antiapoptotic effects of miR-34a. Oncogene. 2011;30(22): 2587-2594.

122. Johnnidis JB, Harris MH, Wheeler RT, et al. Regulation of progenitor cell proliferation and granulocyte function by microRNA-223. Nature. 2008;451(7182):1125-1129.

123. Fazi F, Rosa A, Fatica A, et al. A minicircuitry comprised of microRNA-223 and transcription factors NFI-A and C/ EBPalpha regulates human granulopoiesis. Cell. 2005;123(5): 819-831.

124. Monticelli S, Ansel KM, Xiao C, et al. MicroRNA profiling of the murine hematopoietic system. Genome Biol. 2005;6(8):R71.

125. Ghisi M, Corradin A, Basso K, et al. Modulation of microRNA expression in human T-cell development: targeting of NOTCH3 by miR-150. Blood. 2011;117(26):7053-7062.

126. Watanabe A, Tagawa H, Yamashita J, et al. The role of microRNA-150 as a tumor suppressor in malignant lymphoma. Leukemia. 2011;25(8): 1324-1334.

127. Felli N, Fontana L, Pelosi E, et al. MicroRNAs 221 and 222 inhibit normal erythropoiesis and erythroleukemic cell growth via kit receptor down-modulation. Proc Natl Acad Sci U S A. 2005;102(50): 18081-18086.

128. Cimmino A, Calin GA, Fabbri M, et al. miR-15 and miR-16 induce apoptosis by targeting BCL2. Proc Natl Acad Sci USA. 2005;102(39): 13944-13949.

129. Fabbri M, Bottoni A, Shimizu M, et al. Association of a microRNA/ TP53 feedback circuitry with pathogenesis and outcome of B-cell chronic lymphocytic leukemia. JAMA. 2011;305(1):59-67.

130. Dejean E, Renalier MH, Foisseau M, et al. Hypoxia-microRNA-16 downregulation induces VEGF expression in anaplastic lymphoma kinase (ALK)-positive anaplastic large-cell lymphomas. Leukemia. 2011;25(12):1882-1890.

131. van der Fits L, van Kester MS, Qin Y, et al. MicroRNA-21 expression in CD4+ T cells is regulated by STAT3 and is pathologically involved in Sézary syndrome. J Invest Dermatol. 2011;131(3):762-768.

132. Schramedei K, Mörbt N, Pfeifer G, et al. MicroRNA-21 targets tumor suppressor genes ANP32A and SMARCA4. Oncogene. 2011;30(26):2975-2985.

133. Han YC, Park CY, Bhagat G, et al. microRNA-29a induces aberrant self-renewal capacity in hematopoietic progenitors, biased myeloid development, and acute myeloid leukemia. J Exp Med. 2010;207(3): 475-489.

134. Pekarsky Y, Santanam U, Cimmino A, et al. Tcl1 expression in chronic lymphocytic leukemia is regulated by miR-29 and miR-181. Cancer Res. 2006;66(24):11590-11593.

135. Hackanson B, Bennett KL, Brena RM, et al. Epigenetic modification of CCAAT/enhancer binding protein alpha expression in acute myeloid leukemia. Cancer Res. 2008;68(9):3142-3151.

136. Agirre X, Martínez-Climent JÁ, Odero MD, Prósper F. Epigenetic regulation of miRNA genes in acute leukemia. Leukemia. 2012;26(3): 395-403.

\section{Dovepress}

cancer patient. The manuscript management system is completely online and includes a very quick and fair peer-review system. Visit http://www.dovepress.com/testimonials.php to read real quotes from published authors. 